\title{
TRENDS IN THE DEVELOPMENT OF DIFFICULTY IN THE COMBINATIONS OF A POMMEL HORSE OF ECH SZCZECIN POLAND 2019
}

\author{
Zdravko Kurtev \\ National Sports Academy „Vassil Levski”, Sofia, Bulgaria
}

\begin{abstract}
The aim of this study is to analyze combinations of the individual finals and the finals of the pommel horse and to determine trends in the development of their difficulty.

To achieve the goal, 32 combinations of the individual European Championship held in town Szczecin Poland 2019 were video-analyzed and described.

Diagrams with difficulty of combinations and percentage of high-difficulty elements as well as the reliability of the performance of these elements were drawn.

We found that the difficulty increases with the use of more combined elements (Stockli, Russian wendesswings) and high value elements (Busnari, Keikha, Sohn, Bezugo.)

The established trends will benefit sports pedagogues (coaches) in their future practice.
\end{abstract}

Key words: artistic gymnastic, pommel horse, trends

\section{INTRODUCTION}

Pommel horse is regarded as one of the oldest apparatuses in artistic gymnastics. If we look at the archetype of the present pommel horse, we will notice a significant difference between the two apparatuses. The original apparatus used hundreds of years ago was a wooden horse - a replica of a real horse; its head was bowed low and its neck was in line with its back. In the second part of $18^{\text {th }}$ century, the horse still had a tail but was already without head; its height could be adjusted in a hall so that the apparatus could stand steadily. (Karácsony, Cuk, 1998).

The first apparatus to be called a pommel horse appeared at the beginning of 1800. (www.gymmedia.com). The dimensions of the apparatus were: $41 \mathrm{~cm}$ width, $183 \mathrm{~cm}$ length, straight, cylindrical, with two rounded ends. The height of the two pommels was maximum $9 \mathrm{~cm}, 5-6 \mathrm{~cm}$ in diameter, the distance between them was $49 \mathrm{~cm}$. The pommels were pointed at both ends downward and rounded. The horse was fastened to the floor.
In 1863 the shape of the horse was changed again. It was with a symmetrical body, with raised neck, and the ends of the pommels were like straps. The height of this apparatus could be regulated.

The pommel horse made in the 1920s was much thinner than its predecessor, and the low part of its body went slantwise upward. This apparatus was used even at the Olympic Games in Berlin in 1936. It was $180 \mathrm{~cm}$ long unlike the present ones which are $160 \mathrm{~cm}$ long.

In 1948 the Americans appeared at the Olympic Games with a $160 \mathrm{~cm}$ long horse which was entirely symmetrical. This inspired the federations to order a horse which was shorter than the common 180 $\mathrm{cm}$ ones at the congress in Venice $25-26.08 .1955$. FIG officially announced the length of the horse. (www.janssen-fritsen.agn.info).

Changes in the design of the apparatus lead to a significant development in the difficulty of the elements. 

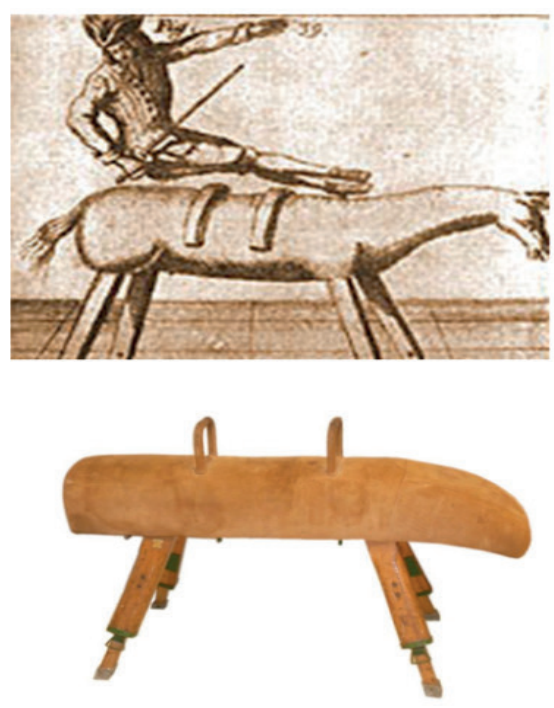
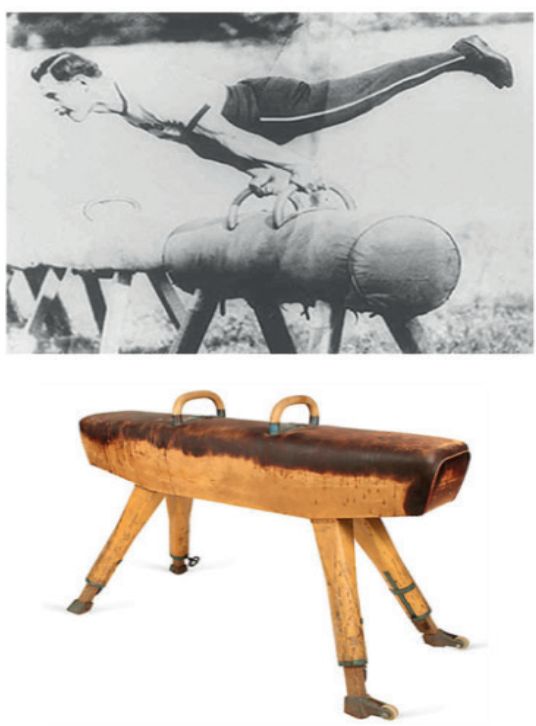
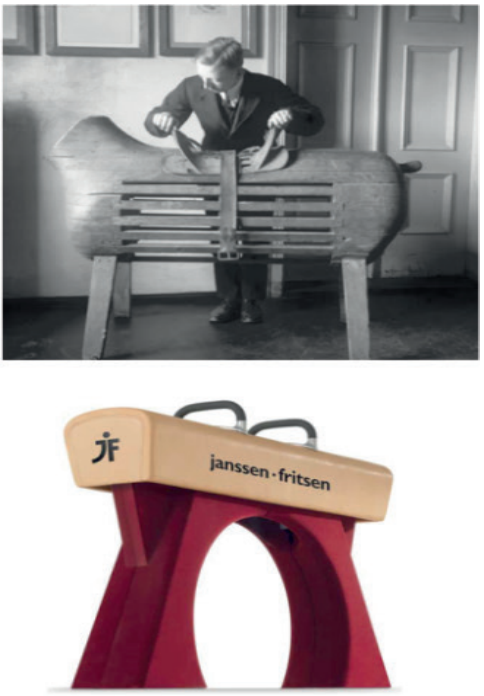

Figure 1. Pommel horse from 1800 to the present

Aim and Objectives of the Study

The aim of the research is to analyze the combinations of the individual finals and the finals of the pommel horse and to determine the trends in the development of their difficulty.

\section{METHODS}

To achieve the goal, 32 combinations of the individual European Championship held in the town of Szczecin Poland 2019 were video-analyzed and described.

The object of study is the elements with difficulty $\mathrm{C}=0.3, \mathrm{D}=0.4, \mathrm{E}=0.5, \mathrm{~F}=0.5$, and combinations of them. A contingent of research, 32 athletes participated in the individual finals and the finale of the pommel horse.

Diagrams with difficulty of combinations and percentage of high-difficulty elements as well as the reliability of the performance of these elements were drawn.

\section{RESULTS}

The international Code of Points changes every four years and aims at decreasing judges' subjectivity when evaluating competitors.

These changes in the new Code of Points for the new Olympic cycle 2016-2020 are related to insignificant changes in the difficulty of some elements such as "Busnari". This element was reduced with one letter from the difficulty - from G 0.7 to F 0.6. Also, in combinations, the elements on one pommel "flops" and "stokli" may not be performed one after the other on one pommel but have to be separated by one middle circle or be performed on a different pommel.

The following pie charts present the percentage ratio of the executed complex elements $(\mathrm{C}=0.3$, $\mathrm{D}=0.4, \mathrm{E}=0.5$, and $\mathrm{F}=0.6$ ) by the competitors who participated in the two finals (the individual finals and the finals of pommel horse) at the European Championship.

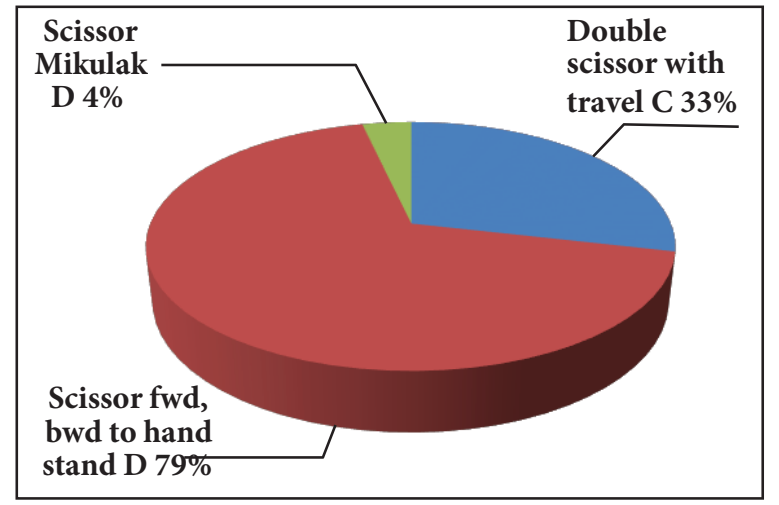

Figure 2. Individual final

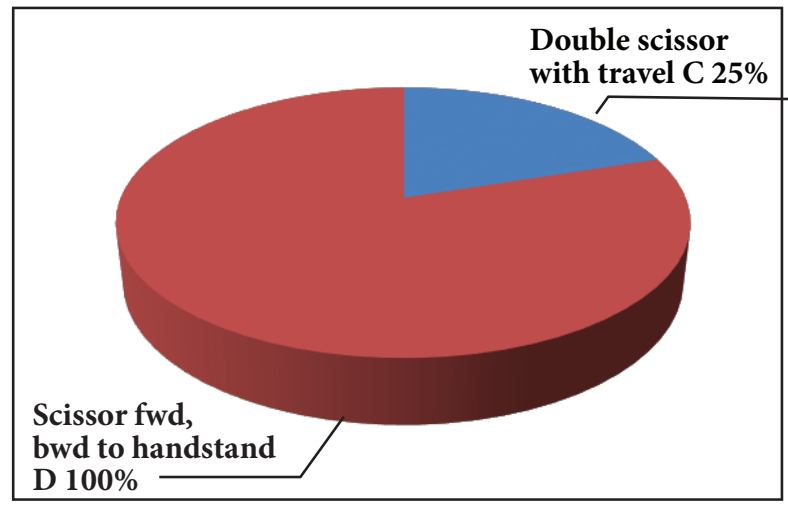

Figure 3. Final of the apparatus 
Figures 2 and 3 show the percentages of the kinds of scissors executed at the two finals. The competitors performed $79 \%$ scissors fwd and bwd to handstand at the individual finals and $100 \%$ scissors fwd

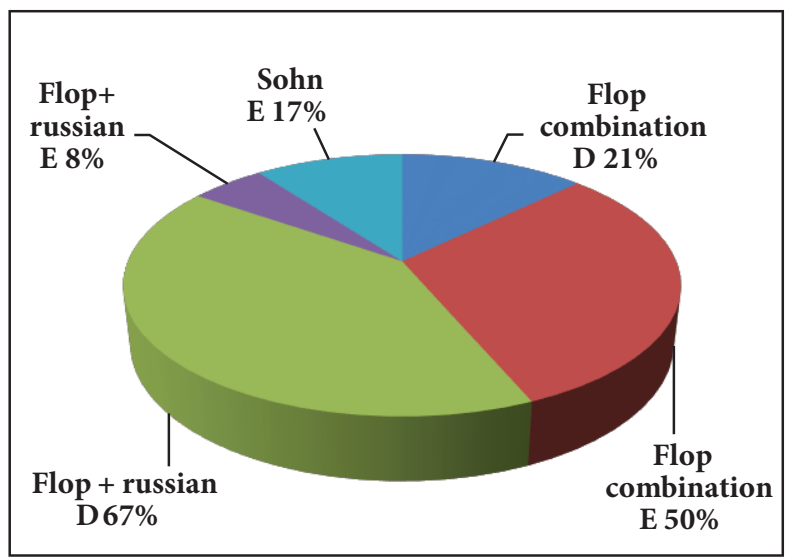

Figure 4. Individual final

The elements from the group of the "circles", "stockli" and the combinations between them are shown in figures 4 and 5. These combinations are characterized with a great difficulty and that is why they are performed by $75 \%$ of the competitors at the finals of the apparatus, and at the individual finals - by $50 \%$. The element Sohn, which is performed by $17 \%$ and $37.5 \%$ respectively at the two finals, is extremely complex but with a high value. The combinations between circles and/or "stocklis"

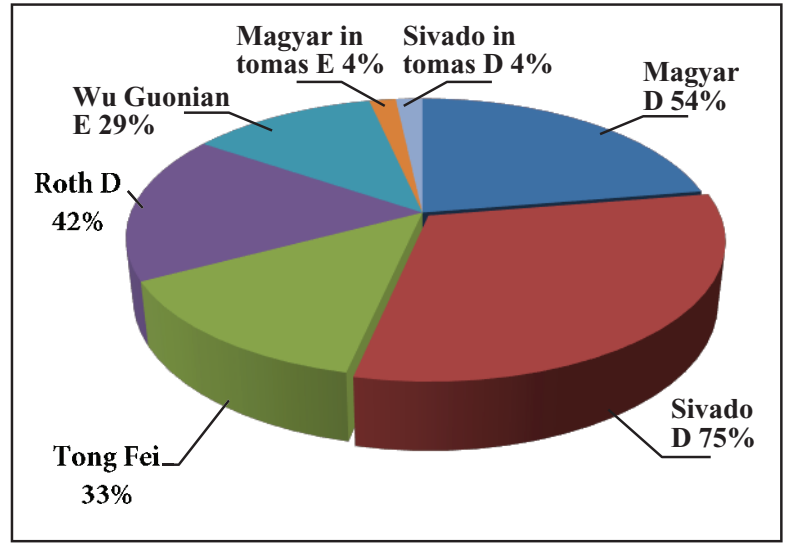

Figure 6. Individual final

The group of transitions is presented in Figures 6 and 7. Here, one of the novelties is the execution of "Magyar and Sivado in Tomas flair" which value is $\mathrm{E}$ and it is one of the highest in this structural group and bwd to handstand at the finals of the apparatus, because its value $\mathrm{D}$ is one of the highest in this structural group.

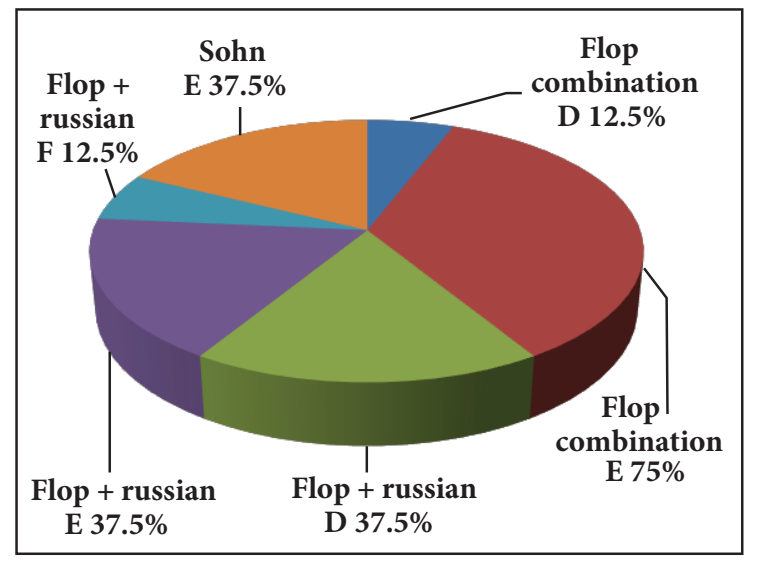

Figure 5. Final of the apparatus

+ Russian wendeswings are also quite used by the competitors. It is of high value $\mathrm{D}, \mathrm{E}, \mathrm{F}$ and is executed by a great number of gymnasts.

The sum of the percentages in the diagrams is more than 100 because the competitors perform more than one element, i.e. they must execute nine elements or combinations (five from one group) from the different structural groups of pommel horse plus dismount.

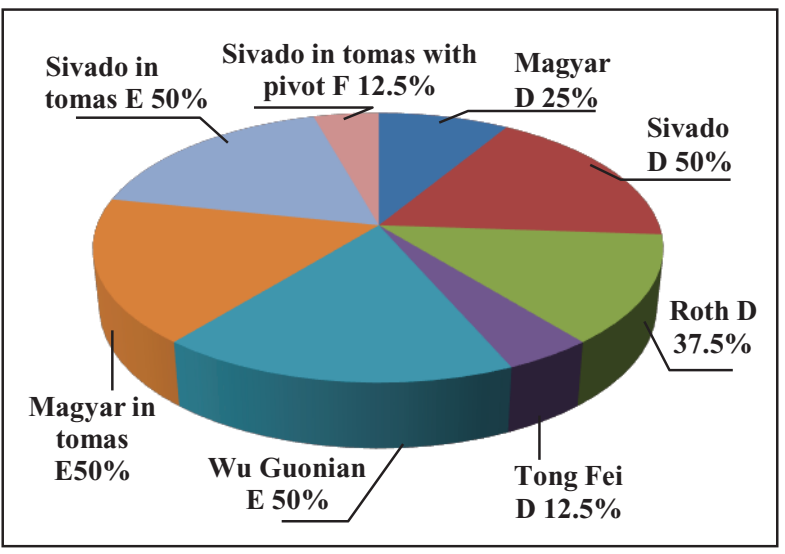

Figure 7. Final of the apparatus

of these elements. It is performed by $4 \%$ at the individual finals and by $50 \%$ at the finals of the apparatus which leads to an increase in the start value. 


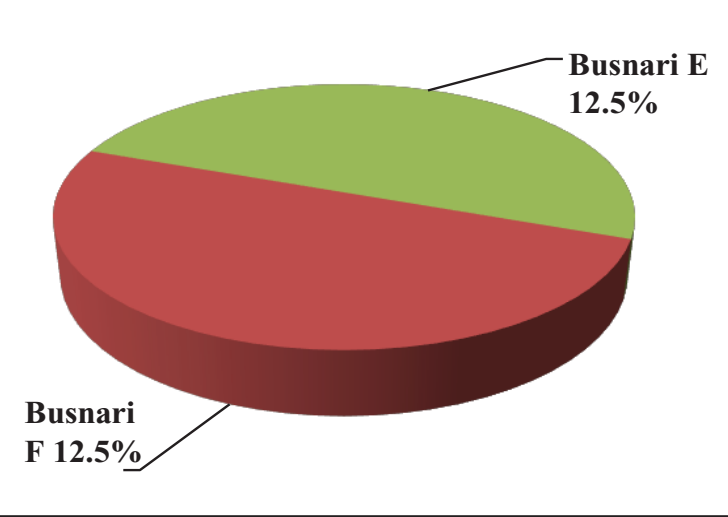

Figure 8. Individual finals
Figures 8 and 9 present the element "Busnari" which has one of the highest values but is rarely used by

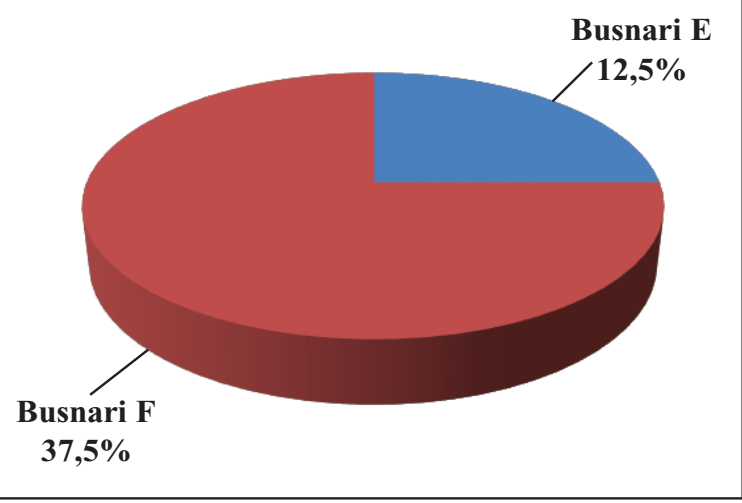

Figure 9. Finals of the apparatus

Figures 10 and 11 show the dynamics of the starts scores of the individual finals and the finals of pommel horse at the European Championship held in the town of Szczecin in Poland.

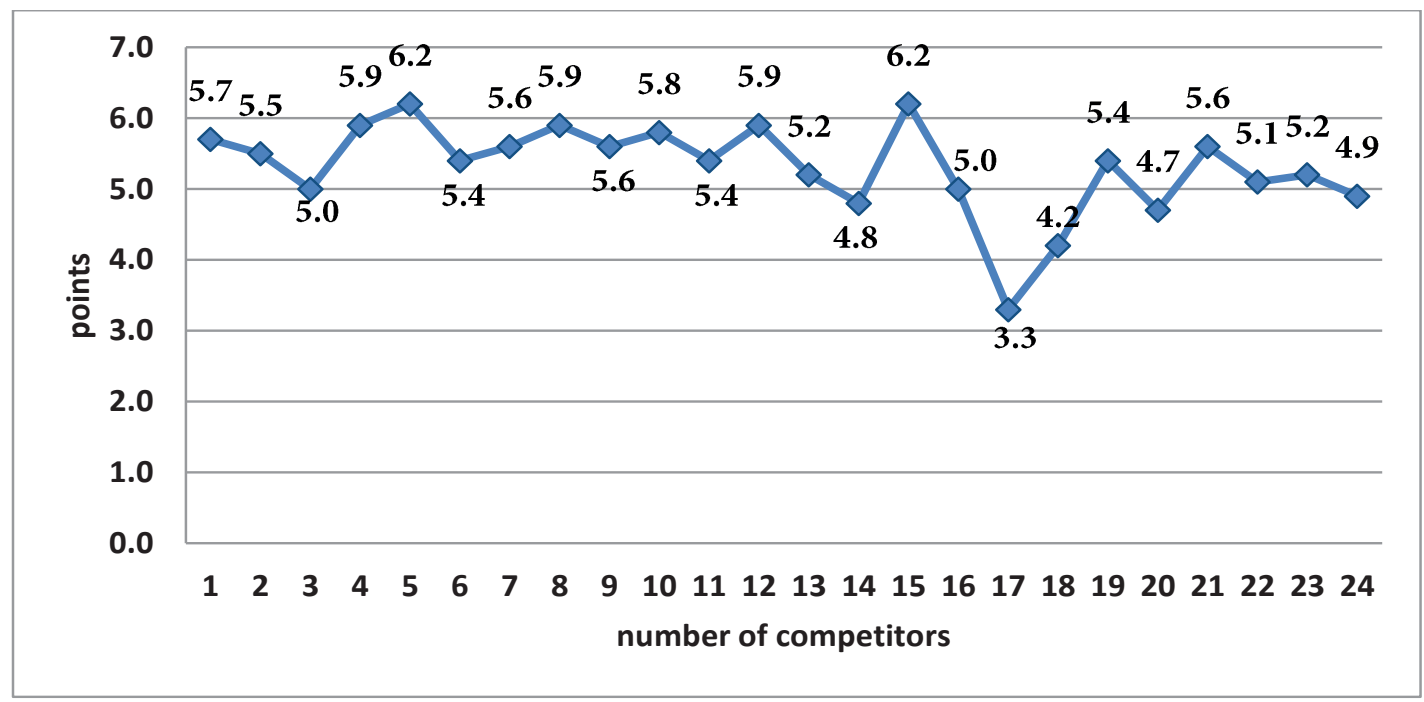

Figure 10. Initial evaluations of an individual final of pommel horse

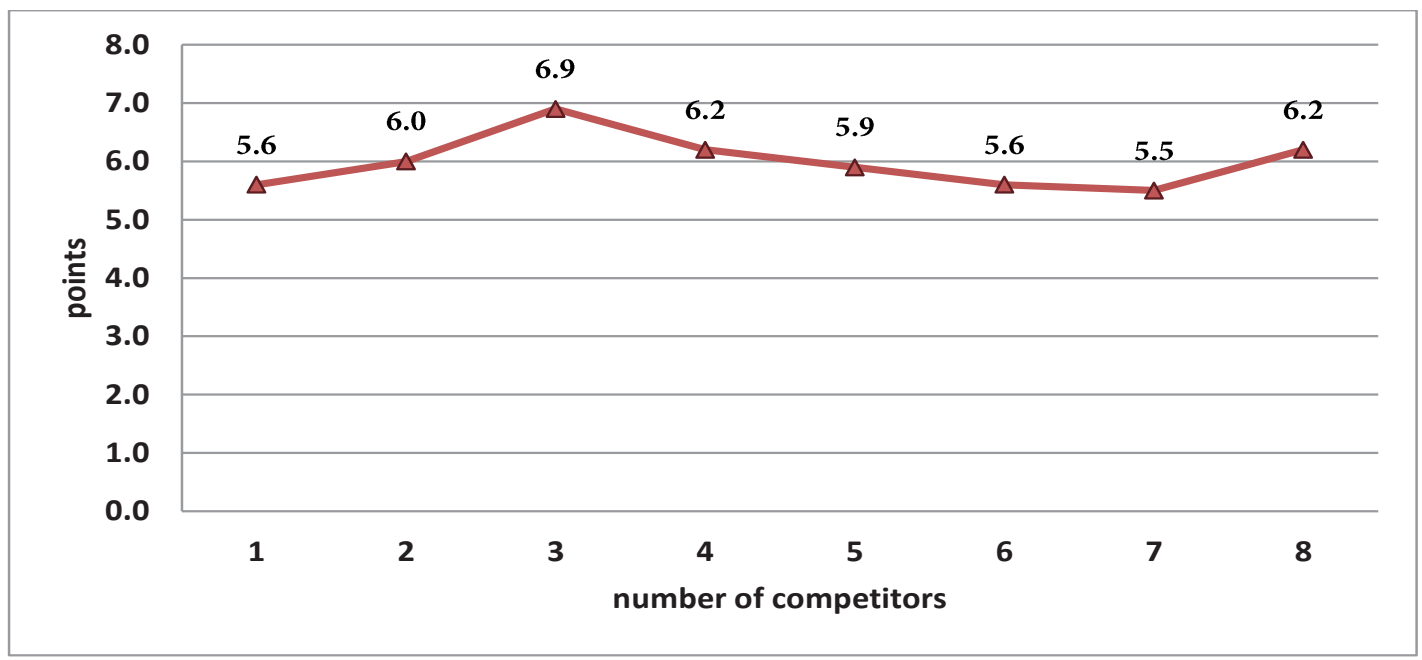

Figure 11. Initial evaluations of final of pommel horse 
We can see that the starts value varied between 3.3 points, which is a low score for the rank of the competition and depends on the complex elements used by a competitor, and 6.2 points, which is a good score for individual finals.

At the finals of pommel horse, the start score were higher - between 5.5 and 6.9 points, which could be explained with the fact that the best competitors on this apparatus on the old continent took part in them and they used very complex elements in their com- binations which led to an increase in the start value. Figures 12 and 13 show the scores for performance of the competitors who took part in the individual finals and the finals of pommel horse. At the first finals these varied from 6.066, which is indicative of falling off the apparatus of a competitor, to 8.500, which is a good score as regards the rules of pommel horse, namely that each circle in the combination executes with an angle in the hip joints is punished.

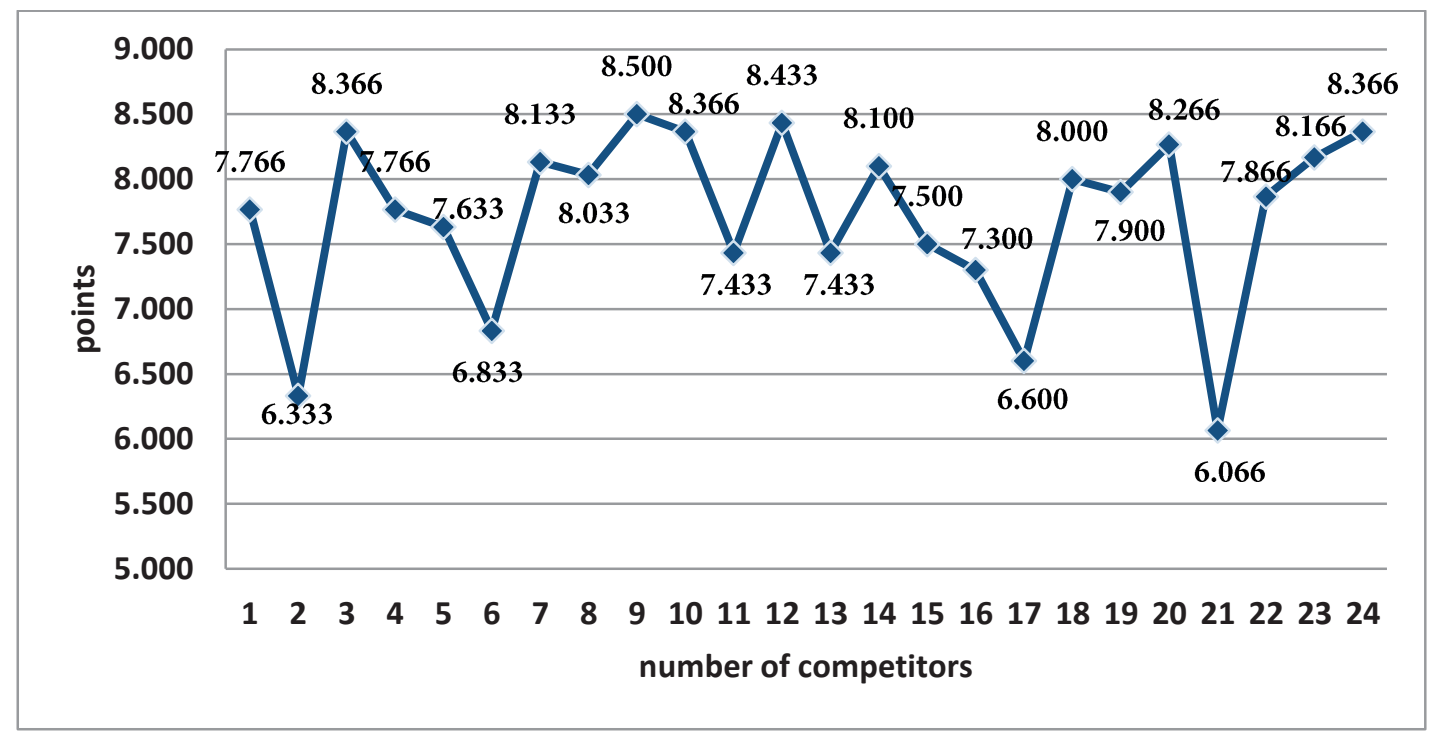

Figure 12. Evaluations for execution of an individual final of pommel horse

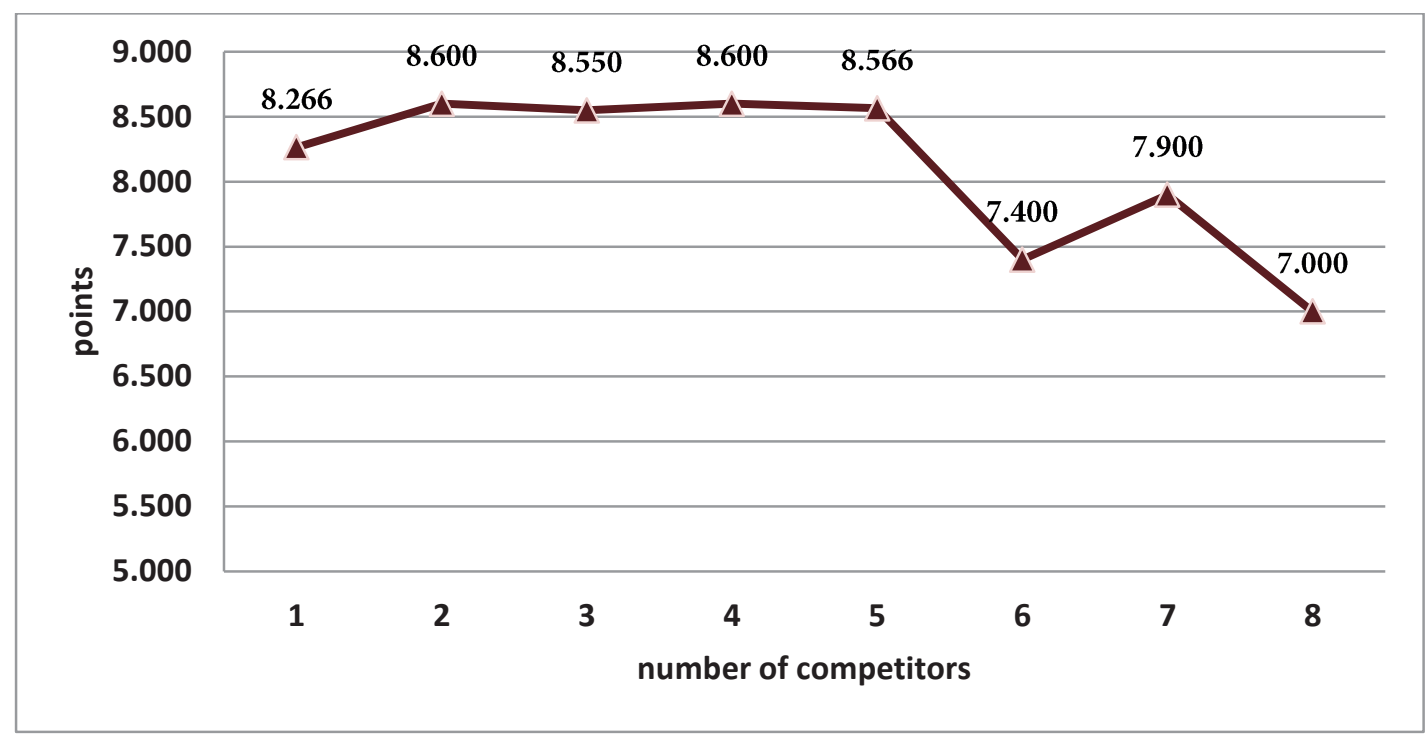

Figure 13. Evaluations for execution of final of pommel horse

The score at the finals of the apparatus were between 7.000 (here the competitor fell off the apparatus which cost him 1.0 punishment) and 8.600 (a score rarely received at this apparatus).

\section{CONCLUSIONS}

The trend in pommel horse is the much higher percentage of the use of circles in straddle position "tomas flair" which leads to an increase in the values of the elements and in the starting score. 
We should increase the number of the elements and combinations from groups $\mathrm{C}, \mathrm{D}, \mathrm{E}$, and $\mathrm{F}$ in order to increase our competitors' score.

\section{REFERENCES}

Karácsony, Is., Cuk, Iv. (1998). Pommel horse exercises: methods, ideas, curiosities, history. Faculty of sport, University of Ljubljana and Hungarian Gymnastics Federation.

Kurtev, Z. (2013). Promenite v sadiyskia pravilnik po sportna gimnastika - mazhe (2013 - 2016 g.) i vliyanieto im varhu nachalnite otsenki na sastezatelnite kombinatsii, Sport i nauka, Izv. br. № 2, pp. 93 - 98.

Code of points Men Artistic Gymnastics 2017-2020.
(2016). Fédération Internationale De Gymnastique.

History of Pommel horse. http://www.gymmedia.com/ ghent2001/appa/pommel/history_ph.htm (Accessed on Sept 10th, 2019)

A Brief History of the Gymnastics Pommel Horse. (2017). https://tenogymnastics.wordpress.com/2017/02/17/abrief-history-of-the-gymnastics-pommel-horse/ (Accessed on Sept 10th, 2019)

\section{Corresponding author:} Zdravko Kurtev, Department of "Gymnastics", National Sports Academy "Vassil Levski" E-mail:zdravko_kurtev@abv.bg 